\title{
Analysis and Experimental Validation of a Space-Vector-Modulation Algorithm for Four-Leg Active Power Filter
}

\author{
Zhenfeng Xiao ${ }^{1}$, Yilong Chen ${ }^{1}$, Rongxiang Yuan ${ }^{2}$ and Xiangtian Deng ${ }^{2}$ \\ ${ }^{1}$ School of Power and Mechanical Engineering, Wuhan University, \\ Wuhan 430072, P.R. China \\ ${ }^{2}$ School of electrical Engineering, Wuhan University, Wuhan 430072, P.R. China \\ zf_xiao@whu.edu.cn
}

\begin{abstract}
This paper analyses the configuration characteristics of the shunt active power filter (SAPF) and introduces a novel dead time control strategy in combination with three dimensional space-vector modulation (3D-SVM) strategies. The steps for the 3D-SVM implementation are identified. The switching vectors, 3D-SVM diagram and duty cycle calculation in abc coordinates, as well as the selection of the tetrahedron are discussed in detail. Moreover, based on the analysis of the APF'S dead-time effect with 3D-SVM control, a novel predictive direct current control algorithm is used for the APF's inverter control. Experimental results together with different control strategy are presented to validate the proposed SVM control strategy for three-phase four-wire system. The experimental results verify the correctness and validity of the proposed $3 D$-SVM scheme.
\end{abstract}

Keywords: Shunt active power filter, three dimensional space-vector modulation, abc coordinate, dead time

\section{Introduction}

With the continuous development of new clean energy in recent years, the power supply methods have become more diverse [1]. In a three-phase four-wire supply system, the operation and application of additional nonlinear loads result in a greater challenge to power quality, causing increasingly serious harmonic imbalance of the three-phase four-wire supply system. Shunt active power filter (APF) is one of the effective methods used to solve these problems [2]. The three-phase four-wire converter has also received considerable attention because of its capability to control the zero-sequence component independently. The common topologies of the shunt APF are the three-leg and the four-leg structures. The three-leg structure usually adopts a split capacitor type structure. However, the disadvantage of this structure lies in the difficulty to control the midpoint voltage balance of the capacitor [3]. A higher capacitance with relatively low dc-bus utilization is required. The four-leg structure requires additional switching devices and is thus more costly than the three-leg structure [5]. However, the four-leg structure has stronger zero-sequence compensation and zero-sequence control, as well as excellent dc-bus utilization [4]. This paper thus focuses on the three-phase four-leg APF.

The commonly used methods of impulse-width modulation in an APF are hysteresis modulation [6], triangular wave modulation, and sinusoidal modulation. Compared with the common modulations, three-dimensional space vector modulation (3D-SVM) [7-10] is characterized by high dc-bus utilization, small harmonic output, and easily achieved computer 
algorithm control. This method has recently been widely studied in the field of converters. The 3D-SVM is used to achieve current control of the APF by coordinating repeat control, proportional-integral (PI) control, and deadbeat control $42 \%$ better than traditional modulation, especially in the three-phase four-wire APF system. The method also reduces $19 \%$ of output waveform distortion.

Several modulation strategies under traditional two-dimensional coordinate systems cannot meet the requirement of the three-phase four-wire system to control the zero-sequence component. Most recent studies on the three-phase four-wire system controlling the zerosequence component are centered on the SVM algorithm [11]. Several studies propose 3D modulation strategies based on the $\alpha \beta \gamma$ coordinate system, and a few studies propose 3DSVM strategies based on the abc coordinate system [12]. However, 3D modulation strategies based on the $\alpha \beta \gamma$ coordinate system provide better ideas and measures to solve the zerosequence current compensation. However, these strategies have some disadvantages [13-15]:

1. The computations in the vector conversion of reference voltage are lengthier and more confusing.

2. Switching the vector expression of the $\alpha \beta \gamma$ coordinate system is metaphorical, and the whole structure of its space vector coordinate system is relatively complicated.

3. Most modulation algorithms based on the $\alpha \beta \gamma$ coordinate system require several regional judgments, and the judgment processes require a large amount of calculation.

Reference [16] proposed a constructive 3D-SVM strategy based on the abc coordinate system, which simplified the process of regional choice and reduced the specific amount of computation compared with the $\alpha \beta \gamma$ coordinate system. This strategy could also be related to studies of the multi-level inverter. However, the research mentioned above barely touches on the dead time control problem in the 3D-SVM of the three-phase four-leg converter based on the abc coordinate system. Research on the abc coordinate is also limited to the simulation and achievement of the three-phase four-leg converter. However, previous studies inspired the application of this method in APF, Static Var Generator (SVG), and other related electric energy equipment. Recent research analysis and application design of the 3D-SVM threephase four-leg converter based on the abc coordinate system in APF has been limited. This study applies three-dimensional space vector modulation based on the abc coordinate to APF analysis and design based on the principle of the four-leg inverter, added a control for dead time, and enhanced the overall compensation effect. Experimental results proved that this method has better application prospects.

This paper proposes a kind of 3D-SVM method based on the three-phase four-leg converter in a shunt active power filter. This method requires limited computation and is easy to perform. Hardware achievement is also easy. A new-type compound current control strategy based on traditional Instantaneous Power Theory was effectively combined with the 3D-SVM method to establish the industrial design of a $100 \mathrm{kVA}$ shunt active power filter. Experiments on the three-phase balanced load compensation and the three-phase unbalanced load compensation proved the correctness and feasibility of the aforementioned programs.

\section{Topology Structure of the Three-phase Four-wire APF}

Figure 1 refers to the overall structure of the three-phase four-wire APF. The topology structure compensates the unbalanced and balanced loads concurrently. In Figure 1, the $C_{d c}$ capacitor is used as the dc electrical energy storage device; the parallel RC filters the high-frequency ripple of the inverter, $i_{s a} i_{s b} i_{s c}$ are grid-side currents; 
$i_{l a} i_{l b} i_{l c}$ are load currents; $i_{f a} i_{f b} i_{f c}$ are APF output currents; $v_{s a} v_{s b} v_{s c}$ are system voltages; and $S_{i j}$ is the switching function.

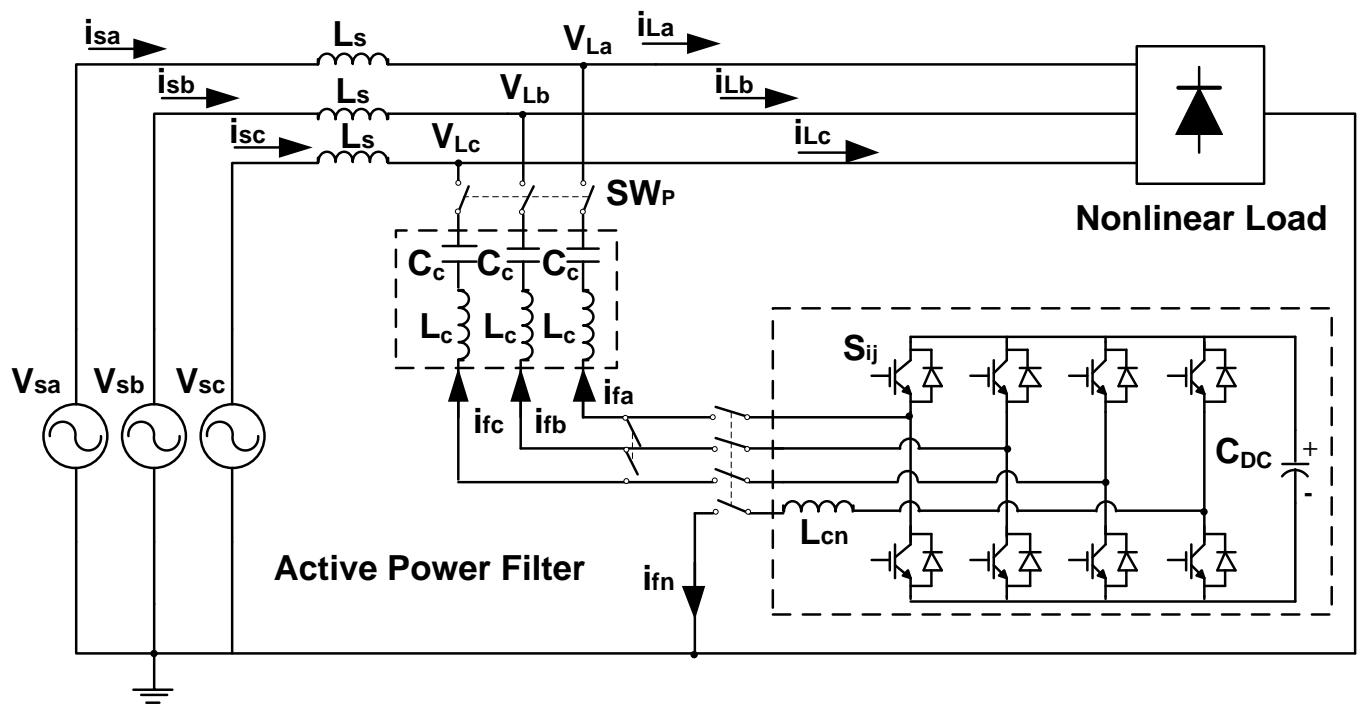

Figure 1. Main electrical circuit structure of three-phase four-leg APF

The figure shows that a leg was added to the three-phase four-leg APF based on the three-phase three-wire APF, which is connected to one of the neutral wires in the threephase four-wire APF to provide a pathway for the zero-sequence current. The added leg directly controls the current and voltage at the neutral point. The increased freedom generates three independent voltages from the three-phase four-leg APF, thus enabling the output of the unbalanced current to compensate for the imbalance in the current. Therefore, the three-phase four-leg structure has a certain advantage relative to the increasing dc-bus current utility and output voltage waveform quality compared with the midpoint structure of the capacitor.

\section{3D-SVM based on the abc coordinate system}

As shown in Figure 1, the topology of the three-phase four-leg inverter consists of four legs: a, b, c, and $\mathrm{f}$. The switching function is defined as $S_{i j}$ and $\mathrm{i}$ refers to the leg; $\mathrm{j}=\mathrm{p}$ refers to the upper leg switch; and $\mathrm{j}=\mathrm{n}$ refers to the lower leg switch. The inverter structure adopted in this study is the two-level structure. The switch is on when $S_{i j}$ is 1 . By contrast, when $S_{i j}$ is 0 , the switch is off. For example, $S_{a n}=1$ indicates that the a-phase lower leg is on, whereas $S_{b p}=0$ indicates that the b-phase upper leg is on. However, the upper and lower switching values at the same phase cannot be on simultaneously, which is represented by $\operatorname{Sip}+\operatorname{Sin}=1$. The voltage vectors in all of the phases can thus be obtained. 


$$
V_{a b c}=\left[\begin{array}{c}
V_{a}-V_{f} \\
V_{b}-V_{f} \\
V_{c}-V_{f}
\end{array}\right]=V_{d c}\left[\begin{array}{c}
S_{a p}-S_{f p} \\
S_{b p}-S_{f p} \\
S_{c p}-S_{f p}
\end{array}\right]
$$

The 16 voltage vectors in Table 1 can be obtained using Eq. (1).

Table 1. Voltage vectors, switching vectors in abc coordinates

\begin{tabular}{|c|c|c|c|c|c|c|c|c|}
\hline State & $S_{a}$ & $S_{b}$ & $S_{c}$ & $S_{f}$ & $V_{a f}$ & $V_{b f}$ & $V_{c f}$ & Voltage vector \\
\hline 1 & 0 & 0 & 0 & 0 & 0 & 0 & 0 & V1 \\
\hline 2 & 0 & 0 & 1 & 0 & 0 & 0 & 1 & V2 \\
\hline 3 & 0 & 1 & $\overline{0}$ & 0 & 0 & 1 & 0 & V3 \\
\hline 4 & 0 & 1 & 1 & 0 & 0 & 1 & 1 & V4 \\
\hline 5 & 1 & 0 & 0 & 0 & 1 & 0 & 0 & V5 \\
\hline 6 & 1 & 0 & 1 & 0 & 1 & 0 & 1 & V6 \\
\hline 7 & 1 & 1 & $\overline{0}$ & 0 & 1 & 1 & 0 & V7 \\
\hline 8 & 1 & 1 & 1 & 0 & 1 & 1 & 1 & V8 \\
\hline 9 & 0 & 0 & 0 & 1 & -1 & -1 & -1 & V9 \\
\hline 10 & 0 & 0 & 1 & 1 & -1 & -1 & 0 & V10 \\
\hline 11 & 0 & 1 & 0 & 1 & -1 & 0 & -1 & V11 \\
\hline 12 & 0 & 1 & 1 & 1 & -1 & 0 & 0 & V12 \\
\hline 13 & 1 & 0 & 0 & 1 & 0 & -1 & -1 & V13 \\
\hline 14 & 1 & 0 & 1 & 1 & 0 & -1 & 0 & V14 \\
\hline 15 & 1 & 1 & 0 & 1 & 0 & 0 & -1 & V15 \\
\hline 16 & 1 & 1 & 1 & 1 & 0 & 0 & 0 & V16 \\
\hline
\end{tabular}

The simple voltage vector under the abc coordinate can be obtained from Table 1, as shown in Figure 2. The space vector chart is clearly a closed dodecahedron crossed by two cubes. The side length of each cube is unit length $\mathrm{Vdc}$. The upper half is a positive vector, whereas the lower half is a negative vector. Zero coordinates refer to two zero voltage vectors. 


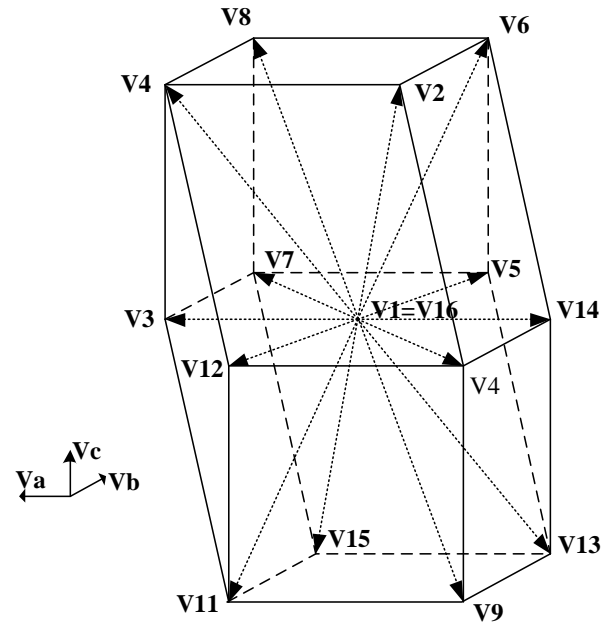

\section{Figure 2. Switching vector figure under the abc static coordinate}

Six of the planes in this polyhedron are parallel to the surface on which the axis is located, as shown in $V_{a}= \pm 1, V_{b}= \pm 1, V_{c}= \pm 1$. Each voltage from phase to midpoint must be less than or equal to the dc-bus voltage Vdc. The other six planes are on a 45 degree plane on which the axis is located, as shown in $V_{a}-V_{b}= \pm 1, V_{b}-V_{c}= \pm 1, V_{c}-V_{a}= \pm 1$. Based on the above expression, the conditions demand the generation of the Table 1 voltage vector.

$$
\begin{aligned}
& \left|V_{a f}\right| \leq 1 ;\left|V_{b f}\right| \leq 1 ;\left|V_{c f}\right| \leq 1 ; \\
& \left|V_{a f}-V_{b f}\right| \leq 1 ;\left|V_{b f}-V_{c f}\right| \leq 1 ;\left|V_{c f}-V_{a f}\right| \leq 1 ;
\end{aligned}
$$

The space voltage vector chart of the abc coordinate system is simpler and clearer than that of the $\alpha \beta \gamma$ coordinate system and is also more suited to judge the reference vector region. The 3D-SVM method based on the abc coordinate judges and synthesizes the reference voltage vector with the 16 specific voltage vectors shown in Figure 3. The detailed steps are as follows:

Step 1: Judgment of the tetrahedron

Step 2: Calculation of action time of non-zero space vector

Step 3: Dead time control

\subsection{Step 1: Judgment of tetrahedron}

The dodecahedron in Figure 3 can be divided into 24 tetrahedrons, as determined from the analysis above. Each tetrahedron consists of three non-zero space vectors and two zero vectors. Therefore, we first judge the tetrahedron containing the reference vector and then define the pointer function of reference vector Vector_Point (VP):

$$
V P=1+\sum_{i=1}^{6} C_{i} \bullet 2^{(i-1)}
$$


The six parameters of $C_{i}$ are defined as :

$$
\begin{aligned}
& C_{1}=\operatorname{Design}\left(\operatorname{int}\left[V_{a f}+1\right]\right) \\
& C_{2}=\operatorname{Design}\left(\operatorname{int}\left[V_{b f}+1\right]\right) \\
& C_{3}=\operatorname{Design}\left(\operatorname{int}\left[V_{c f}+1\right]\right) \\
& C_{4}=\operatorname{Design}\left(\operatorname{int}\left[V_{a f}-V_{b f}+1\right]\right) \\
& C_{5}=\operatorname{Design}\left(\operatorname{int}\left[V_{b f}-V_{c f}+1\right]\right) \\
& C_{6}=\operatorname{Design}\left(\operatorname{int}\left[V_{a f}-V_{c f}+1\right]\right)
\end{aligned}
$$

Where int[ ] refers to the rounding function; and Design() refers to overall sign function, which indicates that when $\mathrm{x}$ is positive, function $\operatorname{Design}(\mathrm{x})=1$, whereas when $\mathrm{x}$ is 0 , $\operatorname{Design}()=0$. All $C_{i}$ should be 0 or 1 . Therefore, the relationship between VP and the

\begin{tabular}{|c|c|c|c|c|c|c|}
\hline $\mathrm{VP}$ & Vector1 & Vector2 & Vector3 & $\mathrm{d} 1$ & $\mathrm{~d} 2$ & $\mathrm{~d} 3$ \\
\hline 1 & V9 & V10 & V12 & $-V c f$ & Vcf-Vbf & -Vbf-Vaf \\
\hline 5 & V2 & V10 & V12 & Vcf & $-\mathrm{Vbf}$ & Vbf-Vaf \\
\hline 7 & $\mathrm{~V} 2$ & V4 & V12 & Vcf-Vbf & Vbf & -Vaf \\
\hline 8 & V2 & V4 & V8 & Vcf-Vbf & Vbf-Vaf & Vaf \\
\hline 9 & V9 & V10 & V14 & $-\mathrm{Vcf}$ & Vcf-Vaf & Vaf-Vbf \\
\hline 13 & $\mathrm{~V} 2$ & V10 & V14 & Vcf & -Vaf & Vaf-Vbf \\
\hline 14 & V2 & V6 & V14 & Vcf-Vaf & Vaf & $-\mathrm{Vbf}$ \\
\hline 16 & $\mathrm{~V} 2$ & V6 & V8 & Vcf-Vaf & Vaf-Vbf & Vbf \\
\hline 17 & V9 & V11 & V12 & $-\mathrm{Vbf}$ & $-\mathrm{Vcf}$ & Vcf-Vaf \\
\hline 19 & V3 & V11 & V12 & Vbf & $-\mathrm{Vcf}$ & Vcf-Vaf \\
\hline 23 & $\mathrm{~V} 3$ & V4 & V12 & Vbf-Vcf & Vcf & -Vaf \\
\hline 24 & V3 & V4 & V8 & Vbf-Vcf & Vcf-Vaf & Vaf \\
\hline 41 & V9 & V13 & V14 & -Vaf & Vaf-Vcf & Vcf-Vbf \\
\hline 42 & V5 & V13 & V14 & Vaf & $-\mathrm{Vcf}$ & Vcf-Vbf \\
\hline 46 & V5 & V6 & V14 & Vaf-Vcf & Vcf & $-\mathrm{Vbf}$ \\
\hline 48 & V5 & V6 & V8 & Vaf-Vcf & Vcf-Vbf & Vbf \\
\hline 49 & V9 & V11 & V15 & $-\mathrm{Vbf}$ & Vbf-Vaf & Vaf-Vcf \\
\hline 51 & V3 & V11 & V15 & Vbf-Vaf & Vaf & Vaf-Vcf \\
\hline 52 & $\mathrm{~V} 3$ & V7 & V15 & Vbf-Vaf & Vaf & $-\mathrm{Vcf}$ \\
\hline 56 & V3 & V7 & V8 & Vbf-Vaf & Vaf-Vcf & Vcf \\
\hline 57 & V9 & V13 & V15 & $-\mathrm{Vaf}$ & Vaf-Vbf & Vbf-Vcf \\
\hline 58 & V5 & V13 & V15 & Vaf & $-\mathrm{Vbf}$ & Vbf-Vcf \\
\hline 60 & V5 & V7 & V15 & Vaf-Vbf & Vbf & $-\mathrm{Vcf}$ \\
\hline 64 & V5 & V7 & V8 & Vaf-Vbf & Vbf-Vcf & $\mathrm{Vcf}$ \\
\hline
\end{tabular}
corresponding non-zero space is obtained after simple calculation, as shown in Figure 2 . The VP value is the basis on which the tetrahedron containing the reference vector can be obtained to determine the three non-zero spaces required for the synthesis of the reference vectors.

Table 2. Vector point, non-zero reference vector and duty cycle

For example, V5, V7, and V8 are randomly selected as non-zero space vectors to make a judgment. Table 1 determines 
V5:(Vaf, Vbf, Vcf) $=(1,0,0) ;($ Vaf-Vbf, Vbf-Vcf, Vaf-Vcf $)=(1,0,1)$;

V7:(Vaf, Vbf, Vcf $)=(1,1,0)$; (Vaf-Vbf, Vbf-Vcf, Vaf-Vcf $)=(0,1,1)$;

V8:(Vaf, Vbf, Vcf $)=(1,1,1) ;($ Vaf-Vbf, Vbf-Vcf, Vaf-Vcf $)=(0,0,0)$;

Eq. (4) determines

V5 : $\mathrm{C} 1=1 ; \mathrm{C} 2=1 ; \mathrm{C} 3=1 ; \mathrm{C} 4=1 ; \mathrm{C} 5=1 ; \mathrm{C} 6=1 ;$

$\mathrm{V7}: \mathrm{C} 1=1 ; \mathrm{C} 2=1 ; \mathrm{C} 3=1 ; \mathrm{C} 4=1 ; \mathrm{C} 5=1 ; \mathrm{C} 6=1 ;$

$\mathrm{V} 8: \mathrm{C} 1=1 ; \mathrm{C} 2=1 ; \mathrm{C} 3=1 ; \mathrm{C} 4=1 ; \mathrm{C} 5=1 ; \mathrm{C} 6=1 ;$

Eq. (3) determines

$\mathrm{V} 5: \mathrm{VP}=1+(1+2+4+8+16+32)=64$

Similarly, V7 and V8 equal to 64 . Thus, the tetrahedron containing the reference vector can be obtained, as shown in Figure 3.

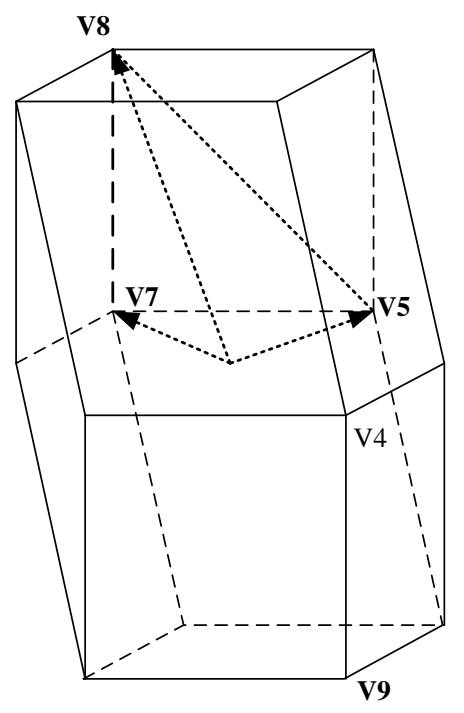

Figure 3. Division of tetrahedron (e.g., VP = 64)

\subsection{Step 2: Calculation of action time of non-zero space vector}

When three non-zero space vectors are confirmed and the region containing the reference vector is determined, the action of the reference vector can be calculated.

Non-zero space vector:

$$
\overrightarrow{V_{\text {ref }}}=M_{d} \bullet \vec{d}=\left[\begin{array}{c}
V_{\text {aref }} \\
V_{\text {bref }} \\
V_{\text {cref }}
\end{array}\right]
$$


where

$$
M_{d}=\left[\begin{array}{l}
\text { Vector } 1 a \text { Vector } 1 b \text { Vector } 1 c \\
\text { Vector } 2 a \text { Vector } 2 b \text { Vector } 2 c \\
\text { Vector } 3 a \text { Vector } 3 b \text { Vector } 3 c
\end{array}\right]
$$

Thus, the non-zero space vector action time obtained is

$$
\vec{d}=M_{d}^{-1} \bullet \overrightarrow{V_{r e f}}=\left[\begin{array}{l}
d_{1} \\
d_{2} \\
d_{3}
\end{array}\right]
$$

The action time of the zero vector is given by $d_{4}=1-d_{1}-d_{2}-d_{3}$. To obtain the minimal total harmonic distortion (THD), the action time of each zero vector should be $d_{4} / 2$ because two zero vectors are present. The action times $t_{a} t_{b} t_{c} t_{f}$ of the switching values in the four legs $\mathrm{a}, \mathrm{b}, \mathrm{c}$, and $\mathrm{f}$ are obtained through a simple calculation. For example, when $\mathrm{VP}=23$, Table 2 serves as reference to obtain the reference vector, which consists of V3, V4, and V12, along with two zero vectors $\mathrm{V0}$ and V16. Table 1 is serves as reference to obtain the switching states of these switching vectors: 0010, 0011, 1011, 0000, and 1111. The corresponding action times are $d_{1}, d_{2}, d_{3}, d_{4} / 2$ and $d_{4} / 2$. Thus, we obtain

$$
\left\{\begin{array}{l}
t_{a}=d_{2}+d_{3} \\
t_{b}=d_{1}+d_{2}+d_{3} \\
t_{c}=0 \\
t_{f}=d_{3}
\end{array}\right.
$$

The abc coordinate system is used to calculate duty rate. $M_{d}$ and $M_{d}^{-1}$ must be 0,1 , or -1 , which simplifies the computation of duty rate to a large extent. The overall process involves simple addition and subtraction. Once VP is obtained with this simple process, the equation above can be the basis on which three non-zero space vectors and the duty rate used to determine the reference vector are obtained. This method is characterized by simple, visual, and minimal calculation compared with conventional methods.

\subsection{Dead time control}

The basic work principle of the conventional APF is to adopt current control algorithms to detect the harmonic current of the compensation object and control the inverter and send harmonic waves of a similar size in the opposite direction for compensation. In practical application, the power switching element in the main electric circuit of an inverter is not ideal. Thus, dead time is set to avoid the straight failure of the inverter. The addition of dead time, with its highlighted effect on compensation, significantly reduces current compensation accuracy and the impact compensation effect. Reference [16] proposed an improved 3D-SVM 
modulation with strong practicality. However, no further investigation and research on the control of dead time was conducted. Several studies have raised solutions in recent years. However, the algorithm is rarely used in APF engineering, which is a field with high realtime requirements. References [17-18] used the error resulting from the difference between the reference signal and the actual signal directly as the control signal by predicting current control to obtain better current control accuracy and lower insulated-gate bipolar transistor (IGBT) switching frequency in the alternating current (AC) motor control field. In this method, sector selection is simpler and requires less computation compared with conventional voltage space vector control, making this method more suitable for application to the field of APF with its high real-time requirements. Therefore, this paper introduces a prediction dc control algorithm to APF control based on the analysis on effect of dead time on APF compensation. A combination with the 3D-SVM algorithm based on the abc coordinate effectively increases compensation accuracy while reducing the effect of dead time.

Several articles has studied the effect of dead time on the inverter and concluded that dead time results in an output voltage with a frequency component six times that of the normal frequency. The APF compensation method aims to mitigate harmonic current dynamically. The main components of the harmonics are the 2nd, 3rd, 5th, 7th, 11th, and 13th harmonic waves, which are obtained by sending the harmonic wave of the electric network several times. High harmonic has a high frequency six times that of the normal frequency component; thus, this harmonic is basically filtered by the output filter. Therefore, dead time predictive compensation is determined by extracting six times the component of the lower harmonic wave using coordinate transformation, detecting the APF output current, and regarding this component as feedback quantity. Reference [18] shows that the error function of the A-phase output voltage relative to dc-bus voltage neutral point is:

$$
\Delta U a_{d c}=\operatorname{design}\left(i_{a}\right) \frac{N T_{d}}{T} U_{d c}
$$

Where $\mathrm{T}$ refers to fundamental cycle, $U_{d c}$ refers to DC voltage, $\mathrm{N}$ refers to the switching number in a fundamental cycle $\mathrm{T}$, and $T_{d}$ refers to dead time. $\operatorname{design}\left(i_{a}\right)$ is defined as

$$
\operatorname{design}\left(i_{a}\right)=\left\{\begin{array}{l}
-1, i_{a}>0 \\
0, i_{a}=0 \\
1, i_{a}<0
\end{array}\right.
$$

Error voltage coefficient $U_{\text {error }}$ is defined as

$$
U_{\text {error }}=\frac{N T_{d}}{T} U_{D C}
$$

Thus, the error of the B-phase voltage and C-phase voltage relative to the dc-bus voltage neutral point can be shown as 
$\left\{\begin{array}{l}\Delta U b_{d c}=\operatorname{design}\left(i_{b}\right) U_{\text {error }} \\ \Delta U c_{d c}=\operatorname{design}\left(i_{c}\right) U_{\text {error }}\end{array}\right.$

Kirchhoff's law is used to obtain the a-phase output voltage error

$\Delta U a n=\left(2 \Delta U a_{d c}-\Delta U b_{d c}-\Delta U c_{d c}\right) / 3$

To obtain the ideal output voltage, the voltage adjustment the inverter should compensate for is actually

$$
\left\{\begin{array}{l}
U a_{c}=\frac{4}{\pi} U_{\text {error }} \sum_{n} \frac{1}{n} \sin (n \omega t-\varphi) \\
U b_{c}=\frac{4}{\pi} U_{\text {error }} \sum_{n} \frac{1}{n} \sin \left(n\left(\omega t-\frac{2}{3} \pi-\varphi\right)\right. \\
U b_{c}=\frac{4}{\pi} U_{\text {error }} \sum_{n} \frac{1}{n} \sin \left(n\left(\omega t-\frac{4}{3} \pi-\varphi\right)\right.
\end{array}\right.
$$

Where, $\mathrm{n}=1,3,5,7,11,13 \ldots$; and $\varphi$ refers to power factor angle.

The dq coordinate is transformed for the above equation, and the output voltage errors of the inverter under dq coordinates $U d_{c}$ and $U q_{c}$, are thus obtained

$$
\left\{\begin{array}{l}
U d_{c}=\frac{4}{\pi} U_{\text {error }}\left(\sin (\omega t)+\frac{1}{5} \sin (5 \omega t)+\frac{1}{7} \sin (7 \omega t)+\frac{1}{11} \sin (11 \omega t)+\frac{1}{13} \sin (13 \omega t) \ldots\right) \\
U q_{c}=\frac{4}{\pi} U_{\text {error }}\left(-\cos (\omega t)+\frac{1}{5} \cos (5 \omega t)-\frac{1}{7} \cos (7 \omega t)+\frac{1}{11} \cos (11 \omega t)-\frac{1}{13} \cos (13 \omega t) \ldots\right)
\end{array}\right.
$$

Under the dq coordinates, the output current error of the inverter can be expressed as:

$$
\left\{\begin{array}{l}
i d_{c}=\frac{4}{\pi} \frac{U_{\text {error }}}{Z}\left[-\sin \varphi+\frac{1}{5} \sin (6 \omega t-5 \varphi)+\frac{1}{7} \sin (6 \omega t-7 \varphi)+\frac{1}{11} \sin (12 \omega t-11 \varphi)+\frac{1}{13} \sin (12 \omega t-13 \varphi)+\ldots\right) \\
i q_{c}=\frac{4}{\pi} \frac{U_{\text {error }}}{Z}\left(-\cos \varphi+\frac{1}{5} \cos (6 \omega t-5 \varphi)-\frac{1}{7} \cos (6 \omega t-7 \varphi)+\frac{1}{11} \cos (12 \omega t-11 \varphi)-\frac{1}{13} \cos (12 \omega t-13 \varphi)+\ldots\right)
\end{array}\right.
$$

The above equations show that the output current error from the dead time of the inverter after the transformation of the dq rotation coordinate can be shown as an overlay of the dc component, with 6 times frequency and 12 times frequency harmonic wave. Only the dc-bus component and the 6 times frequency that of the normal frequency can be considered here because the frequency that is 12 times that of the normal frequency can be filtered. The dcbus component suppresses adverse effects using closed-loop control. A 6 times frequency that of the normal frequency suppresses the adverse effects of dead time by introducing the control quantity of the corresponding frequency into the inverter to modify the given value of the control signal. The specific dead time predictive compensation control block diagram is shown in Figure 4. 


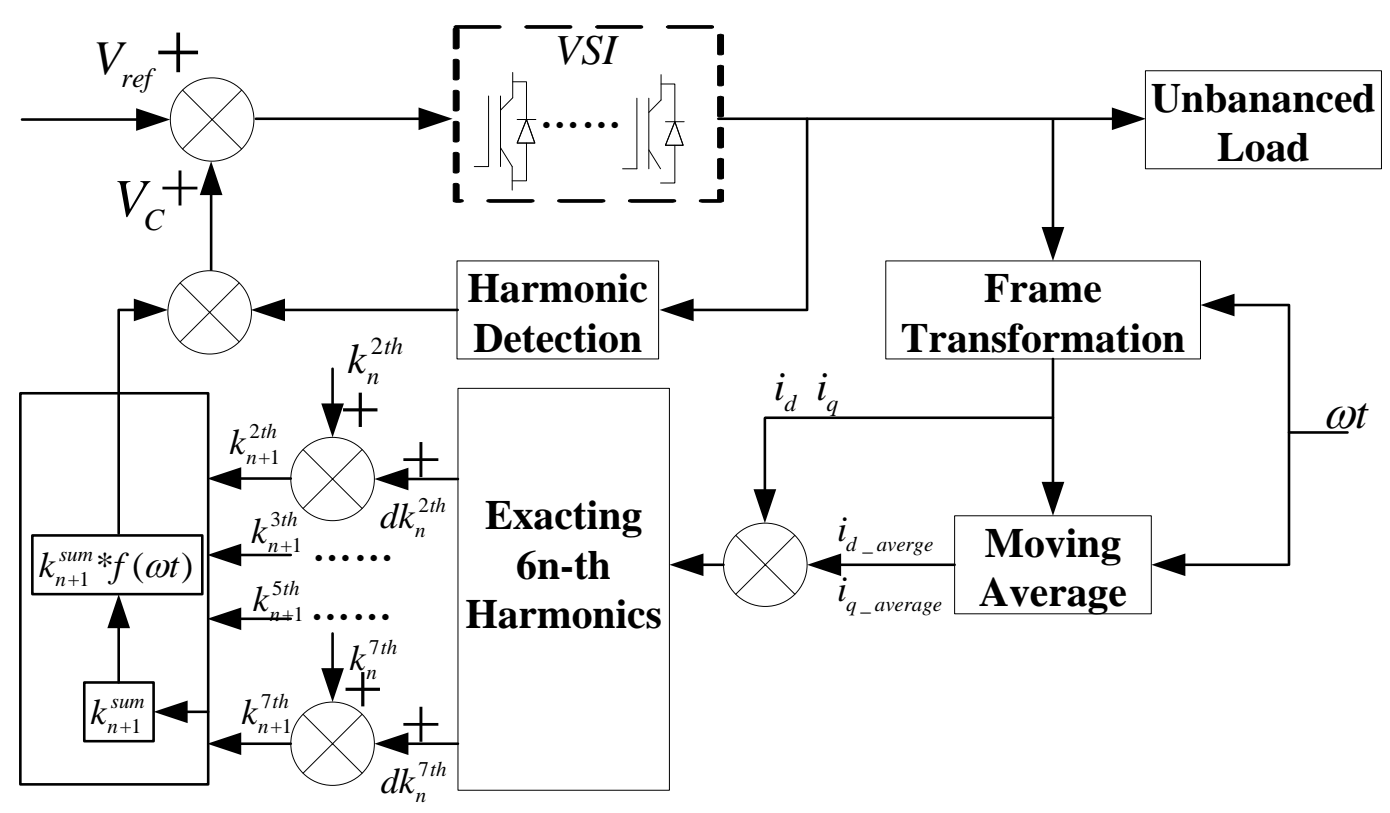

Figure 4. Dead time predictive compensation control block diagram

In this figure, $i_{d_{-} \text {average }}$ and $i_{q_{-} \text {average }}$ refer to the mean value of the axial components $\mathrm{d}, \mathrm{q}$ after coordinate transformation; $k_{n}^{2 \text { th }}$ and $k_{n}^{7 \text { th }}$ refer to the control coefficients of 2nd and 7 th harmonic waves at a certain time; $k_{n+1}^{2 \text { th }}$ and $k_{n+1}^{7 t h}$ refer to the control coefficients of the 2 nd and 7 th harmonic waves at the subsequent time; $d k_{n}^{2 t h}$ and $d k_{n}^{7 \text { th }}$ refer to the adjusting amounts, which are determined by the changes in the frequency component six times that of the normal. Using the 7th harmonic wave as an example, coordinate transformation is used to detect the frequency six times that of the normal and the $\mathrm{d}$ axial component of the APF output of the 7th harmonic wave. The $\mathrm{d}$ axial six times of that of frequency component and current control coefficient $k_{n}^{7 \text { th }}$ are used to obtain control coefficient $k_{n+1}^{7 \text { th }}$ in the subsequent cycle, and the 7th system control coefficient is: $k_{n+1}^{7}=k_{n}^{7}+d k_{n}^{7}$

After multiplying 2nd, 3rd, 5th and 7th harmonic control coefficients, the system control coefficient $k_{n}$ is obtained. Thus, the expression equation of the control coefficient can be obtained: $k_{n}^{\text {sum }}=k_{n}^{2}+k_{n}^{3}+k_{n}^{5}+k_{n}^{7}$,

Where $d k_{n}^{x(t h)}$ refers to the conversion rate of $k_{n}^{x(t h)}$ obtained according to the transformation situation of the APF output. The conversion rate at a certain harmonic is

$$
d k_{n}^{x(t h)}=-k^{\prime}\left|d k_{n-1}^{x(t h)}\right| \bullet \operatorname{design}\left(k_{n}^{x(t h)}-k_{n-1}^{x(t h)}\right) \bullet \operatorname{design}\left(\lambda_{n}-\lambda_{n-1}\right) \quad ; \quad k^{\prime} \quad \text { refers } \quad \text { to the }
$$
accelerated convergence coefficient; $\lambda_{n}$ refers to error accumulation.

The expression of the dead time control principle is: 


$$
\left\{\begin{array}{l}
d k_{n}^{\text {sum }}=-k^{\prime}\left|d k_{n-1}^{\text {sum }}\right| \bullet \operatorname{design}\left(k_{n}^{\text {sum }}-k_{n-1}^{\text {sum }}\right) \bullet \operatorname{design}\left(\lambda_{n}-\lambda_{n-1}\right) \\
k_{n+1}^{\text {sum }}=k_{n}^{\text {sum }}+d k_{n}^{\text {sum }}
\end{array}\right.
$$

\section{Experimental Results}

To verify the accuracy and effectiveness of the control strategy proposed in this paper, generated a $100 \mathrm{kVA}$ three-phase four-wire parallel APF industrial prototype. A double digital signal processing (DSP) processor was used for the controller system. One float DSP chip TMS320F28335 piece finished harmonic detection and the control algorithm, whereas another piece of the DSP chip finished sampling, 3D-SVM, control signal output, and protection. The main power IGBT modules selected, (FF300R12KT4) and 2QD15A17K-C, were used as drive modules. The detailed experimental parameters are shown in Table 3.

Table 3. Technical data of a 100kVA three phase four wires APF experimental system

\begin{tabular}{|l|c|}
\hline System Parameters & Value \\
\hline Capacity & $100 \mathrm{kVA}$ \\
\hline Source, load voltage magnitude & $380 \mathrm{~V} / 50 \mathrm{~Hz}$ \\
\hline Source inductance $L_{s}$ & $1 \mathrm{mH}$ \\
\hline Filtering inductance & $3 \mathrm{mH}$ \\
\hline Filtering capacitance $C_{c}$ & $81.0 \mu \mathrm{F}$ \\
\hline dc storage capacitance $C_{d c}$ & $20 \mathrm{mF}$ \\
\hline dc-link voltage $V_{d c}$ & $700 \mathrm{~V}$ \\
\hline Switching frequency & $10 \mathrm{kHz}$ \\
\hline PWM output mode & Symmetrical PWM \\
\hline
\end{tabular}

All phases of the uncompensated current on the load side of the three-phase four-wire system are shown in Figure 5. The root-mean-square of the A-phase current was $44.7 \mathrm{~A}$; the root-mean-square of the B-phase current was $40.7 \mathrm{~A}$; the root-mean-square of the C-phase current was 42.0 A; and the root-mean-square of the neutral wire current was $21.1 \mathrm{~A}$. The THD of the three ABC phases were 33.6\%, 29.4\% and 29.1\%. Figure 6 refers to the load current waveform after compensation using instantaneous power theory, traditional PI current control theory, and the conventional SVM approach. The traditional method evidently had certain compensative effects on the A, B, and C phases. However, this method did not exhibit a better compensative effect on the neutral wire current. Figure 7 refers to the compensative effect waveform obtained using traditional control theory. The 3D-SVM compensates the neutral wire without specific dead time treatment. The figure shows that the use of 3D-SVM has an evident weakening effect on the harmonic neutral wire current. Neutral wire current was reduced from $21.1 \mathrm{~A}$ to $10.7 \mathrm{~A}$. The overall control program had a particular effectiveness. Figure 8 also shows that after the 3D-SVM based on the abc coordinate and the dead time compensation algorithm proposed in the paper were used, the A, B, and C threephase current waveform on load side was not only more round, but also resembled a sinusoidal waveform more closely. The neutral wire current treatment underwent a considerable change, and the zero wire load current was weaker with a clearer compensative effect. After compensation, the THD of the A-phase was 6.1\%, the THD of the B-phase was $6.0 \%$, and the THD of the C-phase was $5.7 \%$. The root-mean-square of the neutral wire 
current changed from 22.1 A to 8.7 A, reflecting good neutral wire current compensation capability.

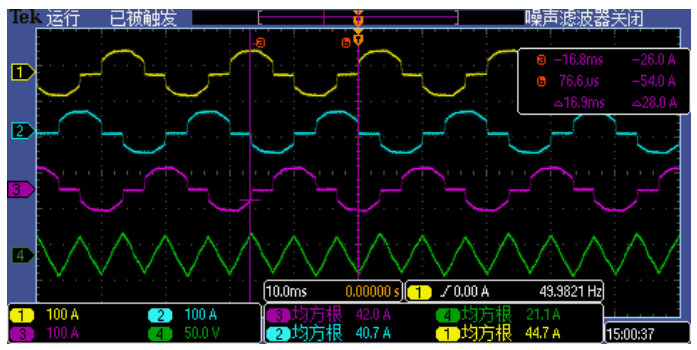

Figure 5. Uncompensated current waveform on the load side

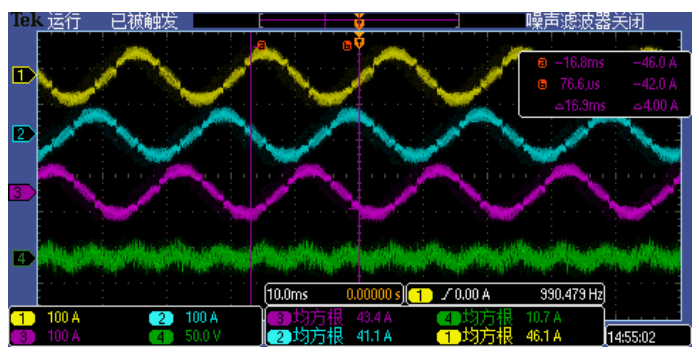

Figure 7. Current waveform on the load side after compensation by 3DSVM without dead control

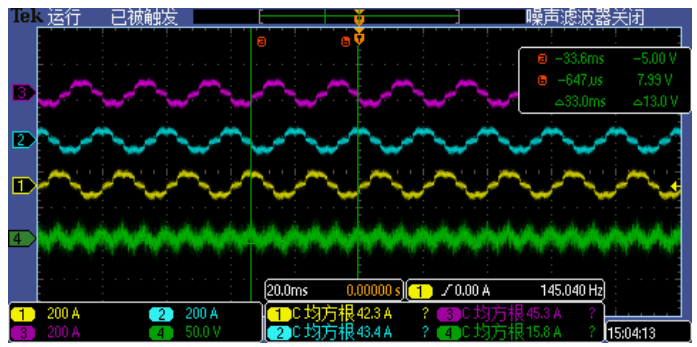

Figure 6. Current waveform on the load side after compensation by conventional SVPWM

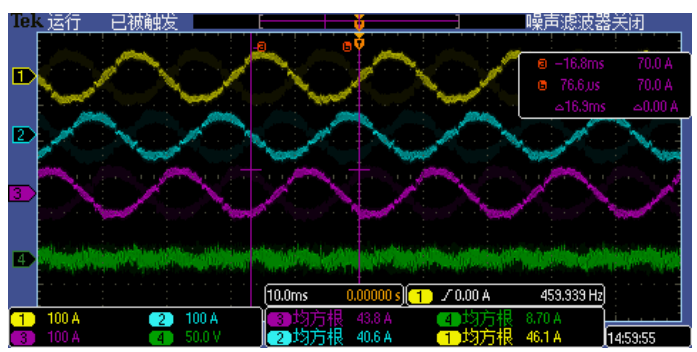

Figure 8. Current waveform on the load side after compensation by 3DSVM with the proposed strategy

The above experiment showed that under the condition of meeting system stability, the new current control strategy and the new 3D-SVM not only improved steady compensation accuracy, but also increased neutral wire current compensation capability using the new dead time control approach compared with conventional current control and the traditional modulation approach.

\section{Conclusion}

This research regarded the three-phase four-leg structure in the three-phase four-wire APF as the object of study. An in-depth analysis and study were performed on the following problems, including the complicated conventional modulation algorithm, the lengthy calculation process, the dead time effect on overall compensation, and the inadequate neutral wire current compensation:

1) A new kind of SVPWM based on abc coordination was analyzed, and the method was applied to research on the three-phase four-leg APF. This method avoided the inadequate neutral wire current compensation of the conventional modulation algorithm, decreased the computation complexity of conventional SVPWM, and enhanced the visibility and operational ease of the algorithm. This method is characterized by the simple, visual, and minimal calculation of duty rate.

2) The aforementioned SVPWM based on abc coordination was improved, and the overall compensation effect was increased further to reduce the adverse effects of dead time on the system. A direct current predictive control algorithm for AC motor control was introduced 
into APF control, and the given value of the control signal was modified by introducing the corresponding control quantity in the inverter to suppress adverse effects of dead time.

3) The proposed algorithm was applied to the research and development of the $100 \mathrm{kVA}$ industrial prototype, and an experimental verification of the prototype was performed based on the conventional algorithm and the algorithm proposed in this paper. The experimental result shows that the algorithm proposed in this paper has good harmonic compensation rate, satisfactory neutral wire compensation, and good dynamic response characteristics in practical operation.

\section{References}

[1] H. Akagi, Y Kanazawa, et al., "Instantaneous reactive power compensators comprising switching devices without storage components", IEEE Trans Ind. Appl, vol. 20, no. 3, (1984), pp. 625-630.

[2] H. Akagi, Y Kanazawa, et al., "Generalized theory of the instantaneous reactive power in three-phase circuits", IEEE\&JIEE, Proceedings IPEC , (1983), pp. 1375-1386.

[3] A. Mohd, E. Ortjohann, et al., "Control strategy and space vector modulation for three-leg four-wire voltage source inverters under unbalanced load conditions", IET Power Electron., vol. 3, (2010), pp. 323-333.

[4] A. Chaghi and A. G. Benoudjit, "Four legged active power filter comensation for a utility distribution system”, J. Electr. Engng, vol. 55, (2004), pp. 31-35.

[5] R. R. Sawant and M. C. Chandorkar, "A multifunctional four-leg grid-connected conmpensator", IEEE transaction on industry application, vol. 45, pp. 249-259.

[6] W. Xiaofeng, D. Yan and H. Xiangning, "Single-carrier modulation and neutral-point balancing method for simplified three-phase three-level diode-clamped rectifier", Proceedings of the CSEE, vol. 26, (2006), pp. 711.

[7] M. Á. M. Prats, G. Escobar, E. Galván, J. M. Carrasco and R. Portillo, "A Switching Control Strategy Based on Output Regulation Subspaces for the Control of Induction Motors Using a Three-Level Inverter", IEEE POWER ELECTRONICS LETTER, vol. 1, (2003), pp. 29-32.

[8] M. M. Prats, R. Portillo, J. M. Carrasco and L. G. Franquelo, "New Fast Space-Vector Modulation for Multilevel Converters Based on Geometrical Considerations", IECON, vol. 4, (2002), pp. 3134-3139.

[9] M. A. M. Prats, J. M. Carassco and L. G. Fraquelo, "Effective space-vector modulation algorithm for multilevel converters", IECON, vol. 4, (2002), pp. 3129-3133.

[10] M. Á. M. Prats, L. G. Franquelo, R. Portillo, J. I. León, E. Galván and J. M. Carrasco, “A 3-D Space Vector Modulation Generalized Algorithm for Multilevel Converters", IEEE POWER ELECTRONICS LETTER, vol. 1, (2003), pp. 110-114.

[11] D. N. Y. Wong, "Three-dimensional space vector modulation with DC voltage variation control in a three-leg centre-split power quality compensator", Electric Power Applications, vol. 151, (2004), pp. 198-204.

[12] R.Cárdenas, R. Peña, M. P. Wheeler and M. J. Clare, "Experimental Validation of a Space-VectorModulation Algorithm for Four-Leg Matrix Converters", IEEE TRANSACTIONS ON INDUSTRIAL ELECTRONICS, vol. 58, (2011), pp. 1282-1293.

[13] X. Li, Z. Deng, Z. Chen and Q. Fei, "Analysis and Simplification of Three-Dimensional Space Vector PWM for Three-Phase Four-Leg Inverters”, IEEE TRANSACTIONS ON INDUSTRIAL ELECTRONICS, vol. 58, (2011), pp. 454-464.

[14] M. A. Perales, L. Terron, J. A. Sanchez, A. De la Torre, J. M. Carrasco and L. G. Franquelo, "New controllability criteria for 3-phase 4-wire inverters applied to shunt active power filters", IECON 02, vol. 1, (2002), pp. 638-643.

[15] M. M. Prats, L. G. Franquelo, J. I. Leon, R. Portillo, E. Galvan and J. M. Carrasco, "A SVM-3D generalized algorithm for multilevel converters", vol. 1, (2003), pp. 24-29.

[16] M. A. Perales, M. M. Prats, R. Portillo, J. L. Mora and L. G. Franquelo, "Three dimensional space vector modulation for four-leg inverters using natural coordinates", Industrial Electronics, 2004 IEEE International Symposium, vol. 2, (2004), pp. 1129-1134.

[17] L. W. Shaojie, "Study of Dead-Time Effect and Its Compensation Strategies", vol. 24, (2009), pp. 112-119.

[18] H. Zhao, Q. M. J. Wu and A. Kawamura, "An Accurate Approach of Nonlinearity Compensation for VSI Inverter Output Voltage”, IEEE TRANSACTIONS ON POWER ELECTRONICS, vol. 19, pp. 1029-1035. 


\section{Authors}

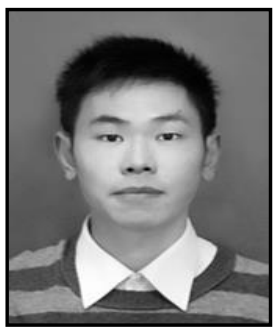

\section{Zhenfeng Xiao}

Zhenfeng Xiao was born in Jiahe, China, in 1985. He received the B.E. degree from China normal university, China, in 2007, and is currently pursuing the Ph.D. degree in School of Power and Mechanical Engineering, Wuhan University, Wuhan, China. His research interests include power quality, adaptive neural control system, power electronics and artificial intelligence of power distribution.

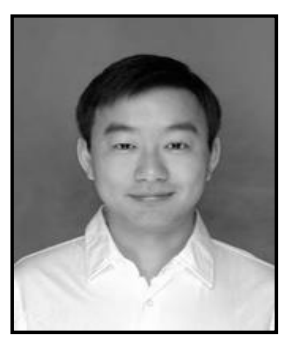

\section{XiangTian Deng}

Xiang Tian Deng received the B.Eng. degree from the China Three Gorges University, China, in 2009. He is currently pursuing the Ph.D. degree in WuHan University. His research interests are power quality, protection of power system, and fault location in power distribution networks. 
International Journal of Control and Automation Vol.7, No.4 (2014) 